\title{
Natural aging, expression of fibrosis-related genes and collagen deposition in rat lung
}

\author{
Carmen Calabresi ${ }^{\mathrm{b}}$, Beatrice Arosio ${ }^{\mathrm{b}}$, Lorenza Galimberti ${ }^{\mathrm{b}}$, Eugenio Scanziani ${ }^{\mathrm{c}}$, \\ Raffaella Bergottini ${ }^{c}$, Giorgio Annoni ${ }^{\mathrm{a}, *}$, Carlo Vergani ${ }^{\mathrm{b}}$ \\ a Department of Clinical and Preventive Medicine, University of Milano-Bicocca, Azienda Ospedaliera S. Gerardo, Monza, Italy \\ ${ }^{\mathrm{b}}$ Department of Internal Medicine, Ospedale Maggiore IRCCS, University of Milan, Italy \\ ${ }^{\mathrm{c}}$ Department of Animal Pathology, University of Milan, Italy
}

Received 5 March 2007; received in revised form 20 June 2007; accepted 26 June 2007

Available online 10 July 2007

\begin{abstract}
Aging lung is characterized by morpho-structural modifications, including progressive fibrosis, that lead to an altered function. Here we provide a comprehensive description of lung collagen expression and metabolism during natural aging of rats. Peribronchial collagen increased significantly in the oldest animals ( $p=0.052$ - vs. 6- and 19-month-old rats), as a consequence of Collagen-I and Collagen-III (COL-I, COL-III) protein accumulation ( $p<0.05$ in 6-, 12- and 19-month-old rats versus the youngest). No changes in fibronectin (FN) protein expression and in COL-III and transforming grow factor $\beta-1$ (TGF $\beta-1)$ mRNA expression were observed. Conversely the transcription activity of the $C O L-I$ gene was overexpressed in the oldest animals $(p<0.05)$.

In the aged rats, the activity of lung matrix metalloproteinases (MMP), MMP-1 and MMP-2, dropped significantly ( $p<0.05$ ), whilst MMP-9 levels were slightly decreased. These changes were associated with a concomitant increase of tissue inhibitors of MMP (TIMP-1 and TIMP-2).

All together, these results suggest that, during natural aging, collagen accumulation in the lung and its progressive fibrosis are mainly due to a reduced proteolytic activity of MMP, in which TIMP-1 and -2 seem to be the major regulating factors.
\end{abstract}

(C) 2007 Elsevier Inc. All rights reserved.

Keywords: Lung; Aging; Fibrosis; Collagen; Matrix metalloproteinases

\section{Introduction}

Aging affects organs, tissues and cell types of the same organism in different ways, resulting in differential rates of functional decline, but all together leading to the diminished ability to meet increased demand (Evers et al., 1994).

In the lung, this phenomenon is characterized by morphological and structural modifications associated with several functional changes (D'Errico et al., 1989). While the total capacity remains almost unchanged, the forced expiratory volume and the forced vital capacity decrease as a result of the diminished elastic forces (Enright et al., 1994; Tack et al., 1982; Peterson et al., 1981).

\footnotetext{
* Corresponding author. Tel.: +39039 2333458; fax: +390392332220.

E-mail address: giorgio.annoni@unimib.it (G. Annoni).
}

The pulmonary plastic deformation during respiration is carried out by the interstitial structures that comprise collagen, elastin, fibronectin, proteoglycans and other molecules, including the basal membranes of the endothelium (Meyer, 2005).

Collagen, the main component of the extracellular matrix (ECM), represents a family of proteins that, together with other ECM constituents, forms a complex network in the pulmonary tissue. There are 11 different types of collagenic proteins in the lung, that account for $15-20 \%$ of the total dry weight of the pulmonary tissue; type I and III (COL I - COL III) are the most representative of these and they comprise approximately $90 \%$ of the total collagen (Chambered and Laurent, 1997).

Most of the newly synthesized collagens are immediately degraded and the extent of this process is primarily regu- 
lated by the metalloproteinases (MMPs). The activity of the MMPs under physiological conditions is carefully regulated at the level of expression and activation or at the step of inhibition by MMP tissue inhibitors (TIMPs) (Angel et al., 1987; Brinckerhoff et al., 1986; Herron et al., 1986). Lasting perturbations of any of these steps can lead to collagen accumulation in the parenchyma (Ebihara et al., 2000; Iyer et al., 1999).

Fibronectin $(\mathrm{FN})$ forms fibrils associated with matrix components and mesenchymal cells in the interstitium and, through specific binding sites, promotes cell adhesion and migration, cyto-differentiation, phagocytosis and cell growth. In the adult lung, FN is specifically localized at the basal membrane, around smooth muscle cells and in the alveolar lining fluid (Limper and Roman, 1992). During the early phase of active fibroplasia, FN production increases dramatically, and this augmentation is associated with the fibroblast proliferation thereafter responsible for excessive synthesis and deposition of the collagenic protein.

The overall balance of ECM deposition can also be affected by a family of growth factors, namely transforming growth factor $\beta$ (TGF- $\beta 1$ ), through a variety of biological activities.

TGF- $\beta 1$ directly increases both the abundance and stability of $C O L-I$ and $C O L-I I I$ transcripts, but it also regulates the expression of several MMPs (Sporn et al., 1987; Ignotz and Massaguè, 1986). In fact, elevated circulating levels of TGF- $\beta 1$ are associated with collagen accumulation and increased amounts of MMP-2 protein and TIMPS mRNA (Mozes et al., 1999).

Since fibrosis is a hallmark of aging in various organs (Abrass et al., 1995), the primary goal of this study was to characterize the gene and protein expression of several lung ECM components (Collagen type I, type III and FN).

Therefore, as an index of the ECM turnover, we measured both levels and activities of some metalloproteinases (MMP1, MMP2 and MMP9) and their inhibitors (TIMP-1 and TIMP-2), and, finally, we investigated the age-dependent change in the mRNA expression of TGF- $\beta 1$.

\section{Material and methods}

\subsection{Animals}

Twenty-four male Sprague-Dawely rats (Iffa Credo S.A., a Charles River Company, Calco, Italy) were studied at 2, 6, 12 and 19 months of age (six animals for each group). On arrival, rats were individually housed for 15 days, with controlled temperature $\left(25^{\circ} \mathrm{C}\right)$ and $12 \mathrm{~h}$ alternate light-dark cycle, then weighed and killed under fentanyl anaesthesia. Procedures involving animals and their care were conducted in accordance with the institutional guidelines, in compliance with the international policies (EEC Council Directive 86/609, OJ L 358, 1, 12 December 1987).

For histological analysis, one of the lungs was perfused with a formalin solution and, after explantation, fixed in
$10 \%$ formalin. The other lung was immediately frozen in liquid nitrogen and stored at $-80{ }^{\circ} \mathrm{C}$ for biochemical and molecular studies.

\subsection{Histology}

The apical, cardiac and basal right lobes were sampled and fixed in $10 \%$ buffered formalin. From each lobe a slice was obtained and embedded in paraffin. The slice was obtained by cutting the main bronchus transversally. From each sample two histological sections of $4 \mu \mathrm{m}$ thickness were cut and, respectively, stained with haematoxylineosin for histo-pathological analysis and with Mallory trichromic for quantitative evaluation of the fibrotic tissue.

The Mallory trichromic stained sections were analyzed using a light microscope (Olympus BX 14) connected to a color digital camera (CoolSNAP-Pro of 4.1 version), since the fibrotic tissue was depicted in blue with this staining. For the evaluation of peribronchial fibrous tissue, a transverse section of a bronchus with an area ranging between 25,000 and $50,000 \mu \mathrm{m}^{2}$ was selected and examined at $100 \times$ magnification. For the evaluation of parenchymal fibrotic tissue, two areas of lung parenchyma with a total area of $0.56 \mathrm{~mm}^{2}$ devoid of medium/large brochial and vascular structures were randomly selected and examined at $100 \times$. The resulting images were processed on a PC Pentium $4 \mathrm{CPU} 1.7 \mathrm{GHz}$ (Fujitsu Computers) and analyzed with a specific software (Image Pro-Plus 4.5) for quantification of the fibrotic tissue.

\subsection{RNA extraction and quantitative $R T-P C R$}

Total RNA was extracted from approximately $100 \mathrm{mg}$ of frozen lung tissue by the acid guanidinium thiocyanate-phenol-chloroform method (Chomczynski and Sacchi, 1987). As previously described by Nicoletti and Sassy-Prigent (Nicoletti and Sassy-Prigent, 1996), to achieve a relative quantitative measurement of RNA by RT-PCR, a range of seven progressive dilutions, obtained by mixing pools of RNA from the two different comparison groups, was prepared in a constant final volume. The comparison between the two samples was determined by the slope of the regression line.

Aliquots of each dilution mix were incubated at $65^{\circ} \mathrm{C}$ for $10 \mathrm{~min}$ with $1 \mu \mathrm{g}$ oligo-dT $12-18$ (Clontech, Italy) and then at $37^{\circ} \mathrm{C}$ for $1 \mathrm{~h}$ with $200 \mathrm{U}$ of Moloney Murine Leukemia Virus reverse transcriptase (Gibco-BRL, Italy) in a buffer containing Tris- $\mathrm{HCl} 50 \mathrm{mM}(\mathrm{pH} 8.3), \mathrm{KCl} 75 \mathrm{mM}$, DTT $10 \mathrm{mM}, 19 \mathrm{U}$ RNasin, and $0.5 \mathrm{mM}$ of each dNTP in a final volume of $20 \mu \mathrm{l}$. For each cDNA, $2 \mu \mathrm{l}$ were amplified in a total volume of $25 \mu$ containing $50 \mathrm{pmol}$ of oligonucleotide primers, $10 \mathrm{mM}$ of each $\mathrm{dNTP}, 1 \times$ polymerase chain reaction (PCR) buffer (Tris- $\mathrm{HCl} 10 \mathrm{mM}$ pH 8.3, $\mathrm{KCl} 50 \mathrm{mM}$ ), $\mathrm{MgCL}_{2} 0.75-1.5 \mathrm{mM}$ and $1.25 \mathrm{U}$ of Amplitaq DNA Polymerase (Promega, Italy). The sequences of the primers used for the amplification are described in Table 1. Each PCR product was run on an ethidium bro- 
Table 1

Primers for PCR amplification

\begin{tabular}{|c|c|c|}
\hline $\begin{array}{l}\text { Target } \\
\text { mRNA }\end{array}$ & Primer sequences & $\begin{array}{l}\text { PCR } \\
\text { cycles }\end{array}$ \\
\hline $5^{\prime} \mathrm{GAPDH}$ & GATGCTGGTGCTGAGTATGT & 30 \\
\hline $3^{\prime}$ GAPDH & TCATTGAGAGCAATGCCAGC & \\
\hline $5^{\prime} \beta$-ACTIN & TTGTAACCAACTGGGACGATATGG & 30 \\
\hline $3^{\prime} \beta$-ACTIN & GATCTTGATCTTCATGGTGCTAGG & \\
\hline $5^{\prime} \mathrm{COL} 1$ & TGCCGTGACCTCAAGATGTG & 28 \\
\hline $3^{\prime}$ COL 1 & CACAAGCGTGCTGTAGGTGA & \\
\hline $5^{\prime}$ COL III & AGATCATGTCTTCACTCAAGTC & 28 \\
\hline $3^{\prime}$ COL III & TTTACATTGCCATTGGCCTGA & \\
\hline $5^{\prime} \mathrm{TGF}$ & CTTCAGCTCCACAGAGAAGAACTGC & 35 \\
\hline $3^{\prime} \mathrm{TGF}$ & CACGATCATGTTGGACAACTGCTCC & \\
\hline $5^{\prime} \mathrm{FBN}$ & ACCTTGACTGCCCAGTGGACAGCG & 30 \\
\hline $3^{\prime} \mathrm{FBN}$ & GCTCACTCTTCTGATTGTTCTTCAG & \\
\hline
\end{tabular}

mide-stained agarose gel and the amount of nucleic acids present was determined by densitometric analysis (IM1D, Amersham Pharmacia Biotech).

\subsection{COL-I, COL-III and FN protein extraction}

Lung samples were homogenized in a collection buffer

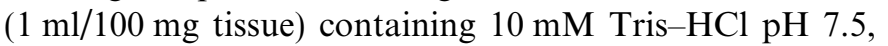
$350 \mathrm{mM} \mathrm{NaCl}{ }_{2}$ and protein inhibitors (Aprotinin $1 \mu \mathrm{g} / \mathrm{ml}$ and Pepstatin-A $10 \mu \mathrm{g} / \mathrm{ml})$, and centrifuged $\left(4{ }^{\circ} \mathrm{C}, 30 \mathrm{~min}\right.$, $12,000 \mathrm{~g}$ ); the supernatant was then recovered and kept on ice. The final protein concentrations were determined with a standardized colorimetric assay (Sigma, Italy); the samples were thereafter divided into aliquots and stored at $-80^{\circ} \mathrm{C}$.

\subsection{COL-I and COL-III Western blot analysis}

Eight micrograms of protein extract, mixed 1:3 with sample buffer $(10 \%$ glycerol, $2 \%$ SDS, $0.25 \mathrm{M}$ Tris- $\mathrm{HCl}$ $\mathrm{pH}$ 6.8, 0.1\% Bromophenol blue, 5\% $\beta$-mercaptoethanol), were boiled for $5 \mathrm{~min}$ and loaded onto an electrophoretic $10 \%$ polyacrylamide gel, according to the methods of Laemmli (Laemmli, 1970).

Electrophoresis was performed at $20-30 \mathrm{~mA}$ for $2-3 \mathrm{~h}$ and the protein bands were blotted onto nitrocellulose at $90 \mathrm{~V}$ for $90 \mathrm{~min}$ at $4{ }^{\circ} \mathrm{C}$. After transfer, non-specific binding was blocked for $1.5 \mathrm{~h}$ with $5 \%$ milk in Phosphate Buffer Saline with $0.1 \%$ Tween 20 (PBST). Membranes were then incubated overnight with the primary antibody mouse antirat COL-I (diluted 1:1500) (Sigma, Italy) and rabbit antirat COL-III (1:2000) (Calbiochem, Italy).

The nitrocellulose membrane was washed three times and antibody binding detected by a secondary antibody after $1.5 \mathrm{~h}$ incubation (for COL-I: anti-mouse peroxides conjugate 1:2000 Sigma, Italy; for COL-III: anti-rabbit peroxides conjugate 1:4000 Amersham, Italy).

The reaction was amplified by Western blot amplification module (Bio-Rad, Italy) and immunoreactive bands revealed by the Opti-4CN substrate (Bio-Rad, Italy) were densitometrically scanned (IM1D, Amersham Pharmacia
Biotech). To test the reproducibility between assays all western blot experiments were run in duplicate and a COL-I/ COL-III standard was loaded in each gel. All data were normalized for beta-actin protein expression (monoclonal anti beta actin, Sigma, Italy was used) to confirm equal loading (Fig. 3a-c).

\subsection{FN ELISA quantification}

Ten micrograms per milliliter of monoclonal antibody anti fibronectin (Chemicon, Italy), diluted in carbonate buffer $\left(0.1 \mathrm{M} \mathrm{Na}_{2} \mathrm{CO}_{3}, 0.1 \mathrm{M} \mathrm{NaHCO}\right.$ ), was coated in an ELISA microtitre and incubated overnight at $4{ }^{\circ} \mathrm{C}$. After blocking for $2 \mathrm{~h}$ with 3\% Bovine Serum Albumin (BSA) in PBST the plate was incubated for $2 \mathrm{~h}$ at room temperature with $100 \mu \mathrm{l}$ of serial dilutions of fibronectin standard (from 0.5 to $0.015 \mu \mathrm{g} / \mathrm{ml}$ ) (Sigma, Italy) and $50 \mu \mathrm{g} /$ well of each sample. Wells were washed and microtitre was incubated with $100 \mu$ of polyclonal anti-fibronectin antibody for $2 \mathrm{~h}$ at room temperature (rat anti fibronectin diluted 1:1000 in PBST) (Chemicon, Italy). An anti-rat alkaline phosphatase conjugated antibody $(1: 3000$ in PBST) (Sigma, Italy) was added and incubated for $1.5 \mathrm{~h}$. The amount of alkaline phosphatase bound to the wells was revealed by the addition of paranitrophenylphosphate substrate. The result was read at $405 \mathrm{~nm}$. Standard absorbance versus its concentration was plotted on graph to construct a standard curve. The concentration of the protein in samples was determined by interpolation of the standard curve.

\subsection{MMP-1, -2 and -9 zymography analysis}

Approximately $50 \mathrm{mg}$ of lung tissue were homogenized with a manual homogenizer in $500 \mu$ of extraction buffer (10 mM cacodylic acid, $150 \mathrm{mM} \mathrm{NaCl}, 20 \mathrm{mM} \mathrm{CaCl}$, $1 \mathrm{mM} \mathrm{ZnCl}_{2}, 1.5 \mathrm{mM} \mathrm{NaNH} \mathrm{H}_{3}$, Triton $\mathrm{X}-1000.01 \%$ ) and thereafter centrifuged $\left(4^{\circ} \mathrm{C}, 5 \mathrm{~min}, 12,000 \mathrm{~g}\right)$; the supernatant was used for total protein assay. The extracts were diluted to a final concentration of $400 \mu \mathrm{g} / \mathrm{ml}$, divided into aliquots and stored at $-20^{\circ} \mathrm{C}$.

Eight micrograms of protein extract, mixed 3:1 with substrate gel sample buffer $(10 \%$ SDS, $4 \%$ sucrose, 0.25 M Tris- $\mathrm{HCl} \mathrm{pH}$ 6.8, 0.1\% bromophenol blue), was loaded immediately without reduction onto an electrophoretic $10 \%$ polyacrylamide gel, containing $1 \mathrm{mg} / \mathrm{ml}$ of type I gelatin for MMP-2, MMP-9 and $1 \mathrm{mg} / \mathrm{ml}$ collagen type III for MMP-1, according to the method of Laemmli. Electrophoresis was performed at $15-20 \mathrm{~mA}$ for $2-3 \mathrm{~h}$ at $4{ }^{\circ} \mathrm{C}$.

After migration, the gels were washed twice with $2.5 \%$ Triton X-100 for a total of $1 \mathrm{~h}$, rinsed in water, incubated overnight at $37^{\circ} \mathrm{C}$ in substrate buffer $(50 \mathrm{mM}$ Tris $\mathrm{HCl}$, $5 \mathrm{mM} \mathrm{CaCl}_{2}, 0.02 \% \mathrm{NaN}_{3}, \mathrm{pH} 8$ ), stained with $0.025 \%$ Commassie Blue, $30 \%$ methanol, $10 \%$ acetic acid and destained in 30\% methanol and 10\% acetic acid. The lysis band dimension, corresponding to MMP activity, was quantified by densitometric scanning and the molecular 
weight of metalloproteinases was identified by co-migration of size markers.

A Western blot analysis for each MMP was also performed in order to demonstrate the specificity of the lysis bands obtained in zymography.

\subsection{TIMP-1 and-2 ELISA quantification}

One-hundred micrograms of lung tissue was homogenized in $200 \mu \mathrm{l}$ of extraction buffer $(20 \mathrm{mM}$ Tris- $\mathrm{HCl} \mathrm{pH}$ $7.5-1 \mathrm{mM} \mathrm{CaCl} 2-0.005 \%$ Brij 35), centrifuged at $10,000 \mathrm{~g}$ at $4{ }^{\circ} \mathrm{C}$ for $20 \mathrm{~min}$ and stored at $-80{ }^{\circ} \mathrm{C}$. The final protein concentration was determined with a standardized colorimetric assay (Sigma-Italy). Undiluted samples were assessed with an ELISA commercial kit for determination of TIMP-1 and 2 protein levels (Amersham, Italy).

Standard and sample were incubated in microtitre wells precoated with anti-TIMP antibodies. After washing, TIMPs were detected with a specific peroxidase conjugated antibody. The amount of peroxidase bound to each well was determined by measuring at $450 \mathrm{~nm}$ after addition of TMB (Tetramethyl Benzidine) substrate. The concentration of TIMPs in each sample was determined by interpolation of a standard curve (provided in the kit).

\subsection{Statistical analysis}

Statistical analysis was performed using the SPSS statistical package (SPSS version 10, Chicago, IL). Comparison between experimental groups was done with one-way analysis of variance followed by Bonferroni post hoc test. All results are expressed as mean \pm standard error of the mean (SEM). A $p$-value of $<0.05$ was considered significant.

\section{Results}

\subsection{Lung expression of fibrosis-related gene}

COL-I gene expression remained essentially similar in rats aged between 2 and 12 months $(1.81 \pm 0.46$, $1.22 \pm 0.24,1.90 \pm 0.26$ ), but significantly peaked in the 19 -month-old rats $(3.34 \pm 0.71,+84 \%$ vs. 6 months $p=0.037)$. By contrast no changes in COL-III mRNA were evident at any age $(2.06 \pm 0.78,2.18 \pm 1.09$, $1.62 \pm 0.78,2.12 \pm 0.55 ; p=0.635$ at $2,6,12$ and 19 months, respectively) (Fig. 1).

$T G F-\beta 1$ gene transcription remained weakly detectable and unchanged throughout the observation time $(0.63 \pm 0.09,0.45 \pm 0.04,0.59 \pm 0.16$ and $0.86 \pm 0.18$ at $2,6,12$ and 19 months respectively; $p=0.168$ ).

Of note, $F N$ mRNA significantly increased at 12 months $(+104 \%, p<0.05)$ with respect to the young rats (Fig. 1).

\subsection{ECM deposition}

\subsubsection{Histology}

Image analysis of trichromic stained sections of the pulmonary lobes showed a progressive accumulation of COL
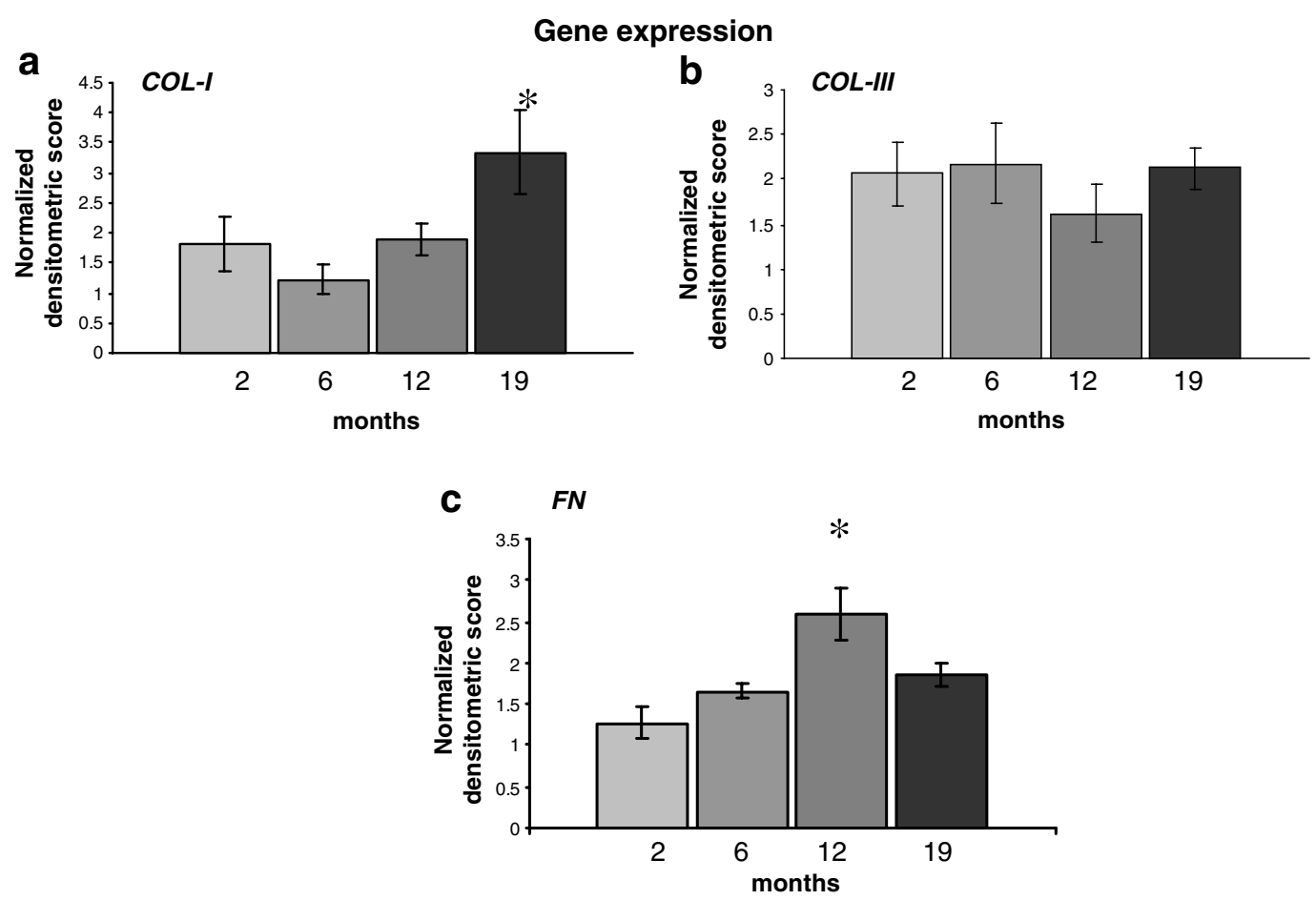

Fig. 1. Bar graph illustrating the age-dependent gene expression of COL-I (a), COL-III (b) and FN (c) in lung homogenates of rats aged 2, 6, 12 and 19 months. Changes in mRNA signal are expressed as normalized optical densities relative to beta-actin $\mathrm{mRNA}$. Values are mean \pm SEM (six animals for age group), ${ }^{*} p<0.05$ vs. 6-month-old rats for COL-I and vs 2 months for fibronectin. 
fibres in parenchymal and peribronchial areas, starting from the age of 6 months, where it reaches statistical significance $(p=0.003)$ (Fig. 2).

\subsubsection{Protein types}

The Western blot immunoreactive bands of COL-I and COL-III (Fig. 3a-c), quantified by densitometric analysis, revealed an accumulation of both collagens throughout maturation and aging. In fact, COL-I reaches its maximum at 6 months $(+876 \%)$ and maintains similar levels in 12and 19-month-old rats $(+661 \%,+794 \%$ respectively, $p=0.000)$, while for COL- III an increase of $+83 \%$, $+95 \%,+114 \%(p<0.05)$ was observed in $6-, 12-$ and 19 month-old rats, respectively, compared with 2-month-old rats (Fig. 3b-d).

\subsubsection{Fibronectin protein quantification}

By contrast, aging did not significantly modify the protein levels of $\mathrm{FN}$, that remain similar in each age group $\quad(1.01 \mu \mathrm{g} / \mathrm{ml} \pm 0.05, \quad 0.95 \mu \mathrm{g} / \mathrm{ml} \pm 0.07, \quad 1.04 \mu \mathrm{g} /$ $\mathrm{ml} \pm 0.17,0.71 \mu \mathrm{g} / \mathrm{ml} \pm 0.07$ at $2,6,12$ and 9 months, respectively).

\subsection{ECM degradation}

\subsubsection{Metalloproteinases activity}

Zymography confirmed an age-dependent diminution of the activity of all the analyzed metalloproteinases (Fig. 4a-c).

MMP-1 was highly reduced by aging: $-315 \%(p<0.05)$ $-322 \%(p<0.05),-856 \%(p<0.05)$ in the 6-, 12- and 19month-old rats, respectively, compared with the young animals (Fig. 4b). A similar pattern was observed for MMP-2 (Fig. 4d) where the decrease was $-61 \%(p<0.05),-50 \%$ $(p<0.05),-69 \%(p<0.05)$ in the same age groups, compared to the young rats. We also observed a weak reduction for MMP-9 during the considered life span.

\subsubsection{TIMP quantification}

The protein levels of TIMP-1 and TIMP-2, increased in 6-, 12- and 19-month-old rats compared to the young ones. This was more evident for TIMP-1 in the old rats $(+171 \%$, $+165 \%,+176 \%$ in $6,12,19$ months, respectively, $p=0.024$ ) (Fig. 5a), while for TIMP-2 there was a moderate increase

\section{Lung parenchyma: cardiac lobe}

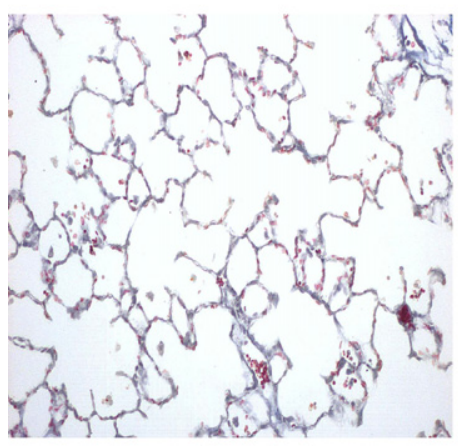

2-month-old rats

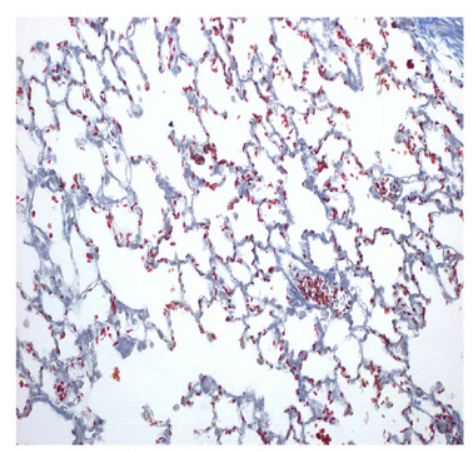

6-month-old rats

Bronchus: basal Lobe

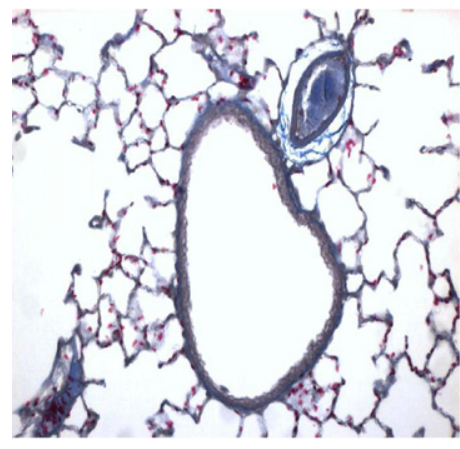

2-month-old rats

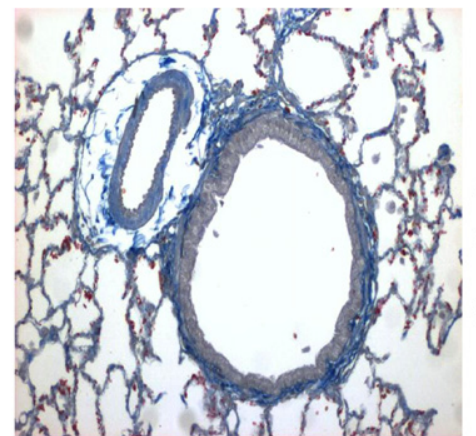

6-month-old rats
Parenchymal fibrosis

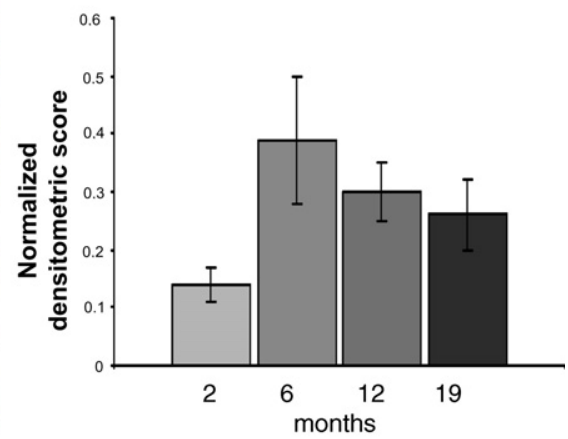

Peribronchial fibrosis

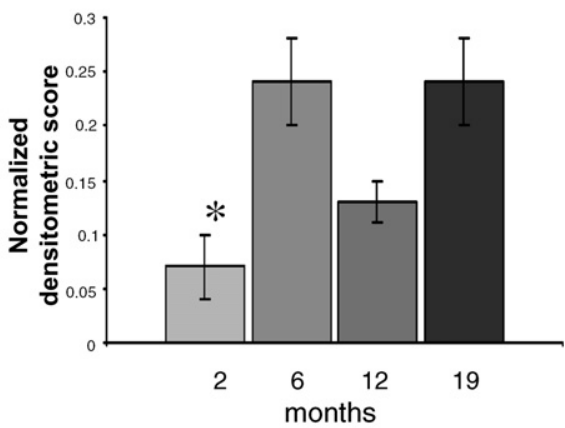

Fig. 2. Microphotographs showing a trichromic staining of a lung section. The fibrous connective tissue is selectively stained in blue. The comparison between 2-month-old and 6-month-old rats show an increase in the amount of parenchymal and peribronchial fibrous tissue. Bar graph illustrating the age-dependent morphometric quantification of age-related changes in lung collagen evaluated by trichromic staining. ${ }^{*} p=0.003$ vs 6 and 19 months. (For interpretation of the references to color in this figure legend, the reader is referred to the web version of this article.) 


\section{COL-I protein}

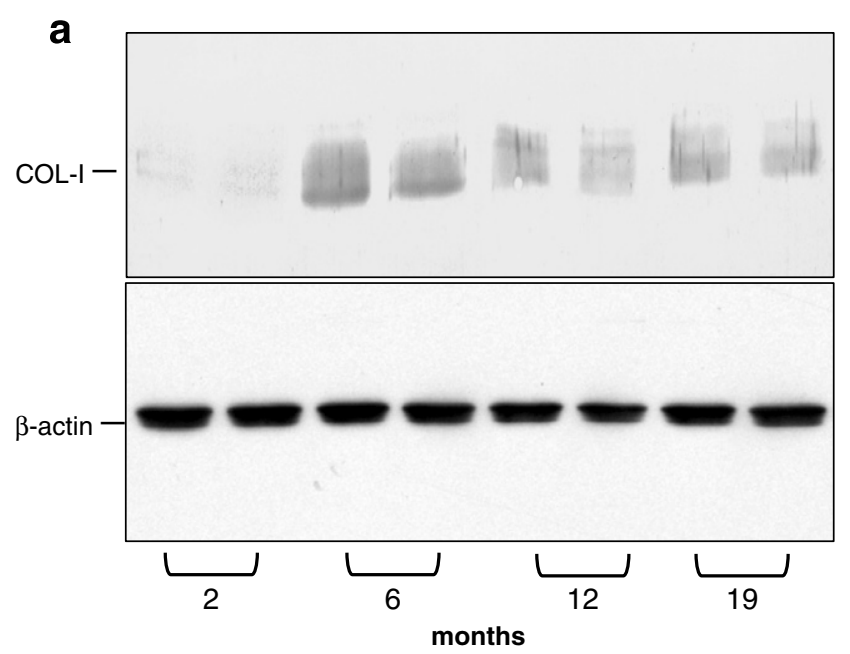

b

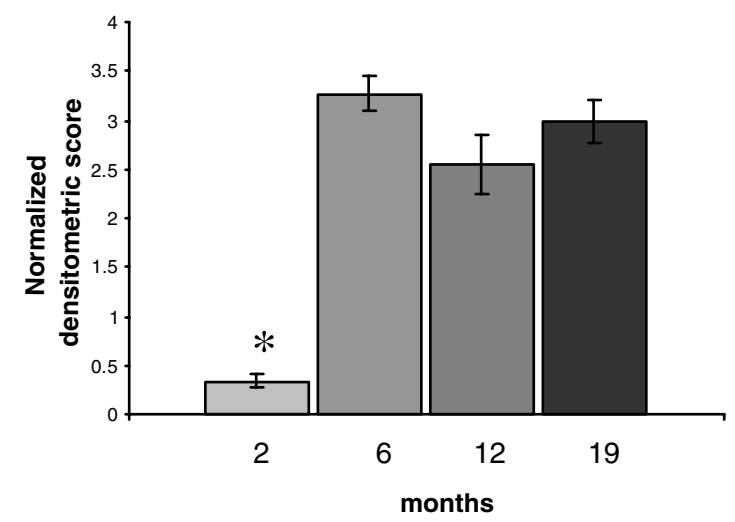

COL-III protein

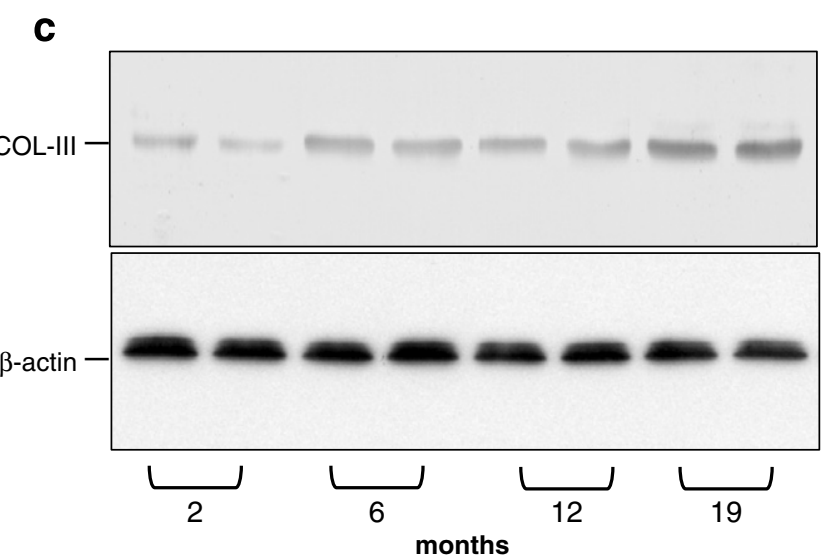

d

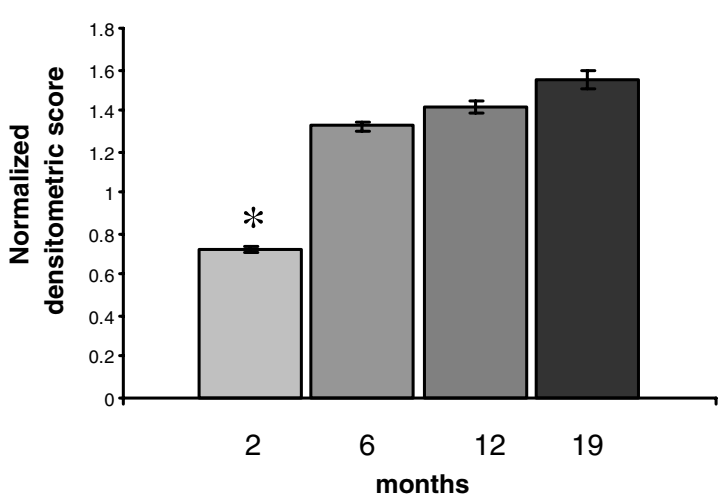

Fig. 3. Western blot analysis of COL-I (a), COL-III (c) protein levels normalized to $\beta$-actin (a-c) in lung homogenates of 2-, 6-, 12- and 19-month old rats. Each lane refers to one animal. Bar graph illustrating the age-dependent COL-I (b) and COL-III (d) protein levels. Data are reported as normalized densitometric score after scanning of the immunoreactive bands. Values are mean \pm SEM. ${ }^{*} p<0.05$ vs $6,12,19$ months.

only in the oldest group of rats compared to the youngest group ( $p=0.339$ ) (Fig. 5b).

\section{Discussion}

Clinical observations suggest that many respiratory disorders appear mostly in old age and that the prevailing pathologies are certainly those involving remodelling of airways and distal lung parenchyma (Malik et al., 2004; Lundback et al., 2003; Janssens et al., 2001).

Since fibrosis interferes with respiratory function, a better knowledge of the basic mechanisms that control this process in the lung would be useful (Green and Pinkerton, 2004).

Up to now, most published data relate to specific pathological conditions, but little is known about the progressive age-dependent modifications.

In this report we combined various analytical approaches and attempted to characterize some of the complex regulatory mechanisms that control the turnover of ECM proteins during lung maturation and aging.

With histopathological analysis and Mallory trichromic staining, combined with quantitative computerized image analysis, we demonstrated a gradual collagen accumulation during aging. This process involved the whole alveolar structure and became particularly remarkable in the peribronchial structure.

Analyzing the single ECM components, COL-I and COL-III appeared to be the main components involved, while FN was less affected.

COL-I expression was upregulated both at mRNA and protein levels during aging, while we found the opposite behaviour for COL-III mRNA, whose levels remained unchanged during aging despite increased protein expression. Similar results have been already described in the aging liver (Gagliano et al., 2002), suggesting two different mechanisms of regulation of these proteins. In the case of COL-III we can hypothesize that the occurrence of post 


\section{Metalloproteases activity}

MMP-1
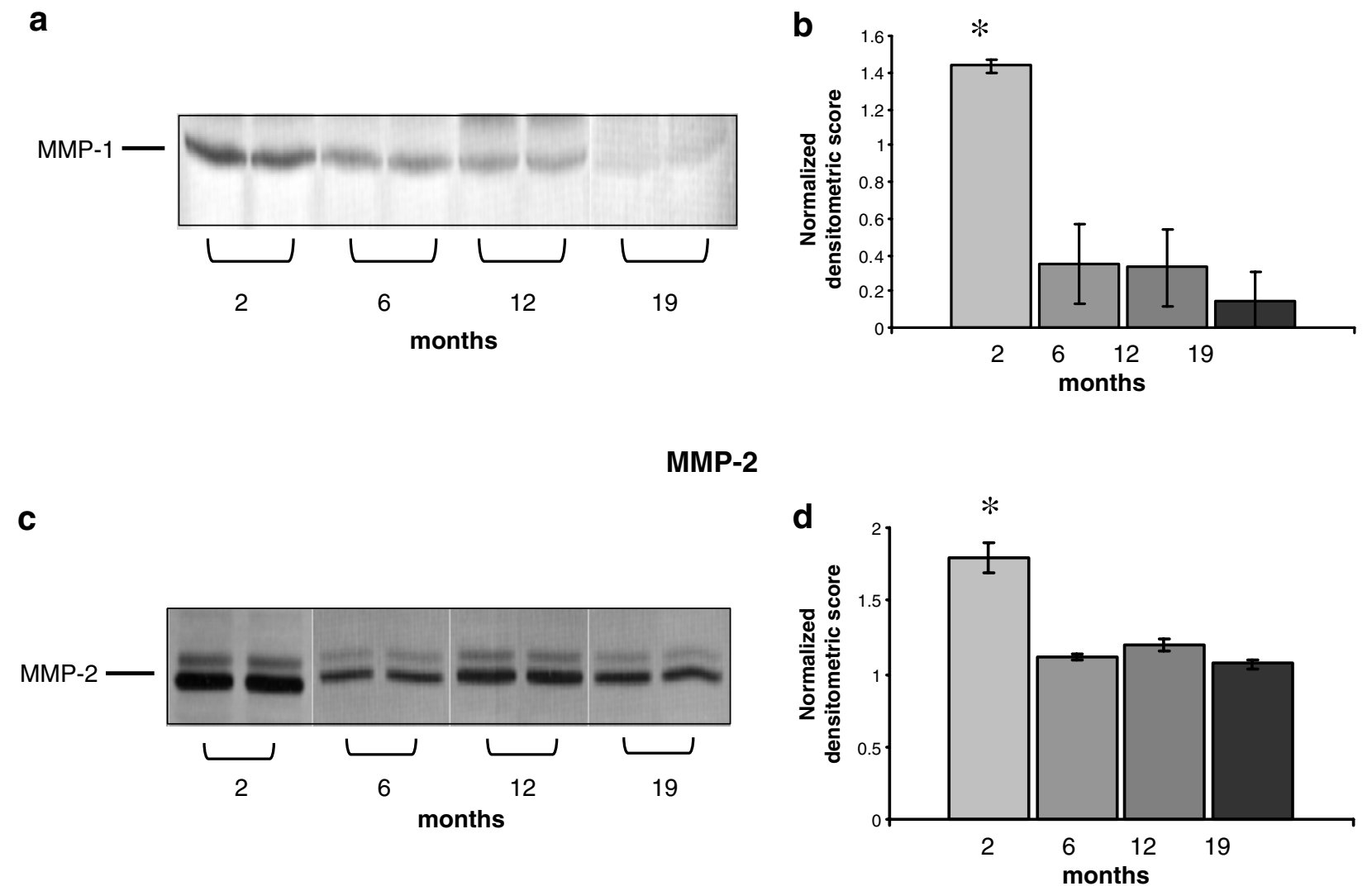

Fig. 4. Representative gelatin Zimogram of gelatinase activity of MMP-1 (a) and MMP-2 (c). Each lane refers to a single animal. Bar graph illustrating the age-dependent expression of MMP-1 (b) and MMP-2 (d) enzymatic activity. ${ }^{*} p<0.05$ vs $6,12,19$ months.

translational modifications, such as the increase of molecular cross-links, and/or an altered balance between synthesis and degradation could be regulating factors.

Finally, since COL-I is commonly more widely expressed in the lung (Chambered and Laurent, 1997), we could speculate that for this reason, the above mentioned effect was detectable mainly for this specific collagenic protein and not for COL-III. It is not easy to explain the drop in peribronchial fibrosis observed in 12-month-old animals. However this finding should not be considered artifactual since it was in line with the quantitation of COL-I with Western blot analysis.

In all groups of rats, the minor change observed in $\mathrm{FN}$ protein expression shows that this protein seems to be predominantly involved in the early phase of active fibroplasia (Limper and Roman, 1992).

Interestingly, in the same samples, $T G F \beta-1$ mRNA levels were always barely detectable and probably unaffected by aging.

Indeed, TGF $\beta-1$ expression is upregulated in active fibroplasia such as in scleroderma, a complex autoimmune disease. This hypothesis is supported by the observation that lung fibrosis could be prevented in mice with Sclerodermatous Graft-Verus-Host Disease (Scl GVHD) by inhibiting TGF $\beta-1$ with neutralizing antibody (McCormick et al., 1999).

It is widely known that collagen levels are fixed through a fine regulation between synthesis and degradation, so that an enhanced synthesis rate and/or slower breakdown could modify the final deposition (Arthur, 1990). In particular, collagen catabolism is determined by MMPs and although the catalytic activity of these enzymes has been implicated in many physiological processes of the lung by participating in branching morphogenesis, homeostasis and repair, most attention has concentrated on physiological pulmonary development rather than normal aging (Parks and Shapiro, 2001).

MMPs are thought to be responsible for the turnover and degradation of connective tissue proteins and their activity is closely regulated in the extracellular space by a process of activation and/or proteolytic cleavages within the matrix environment so that any mismatch in this process could result in excessive ECM accumulation or degradation (Steward, 1999; Tierney et al., 1999).

Interstitial collagenase, or MMP-1, cleaves the native triple helix of interstitial collagen into two fragments, named gelatine fragments, that are then degraded by other proteinases such as MMP-2 (gelatinase A) and MMP-9 (gelatinase 
Tissue inhibitor of metalloproteases TIMP-1
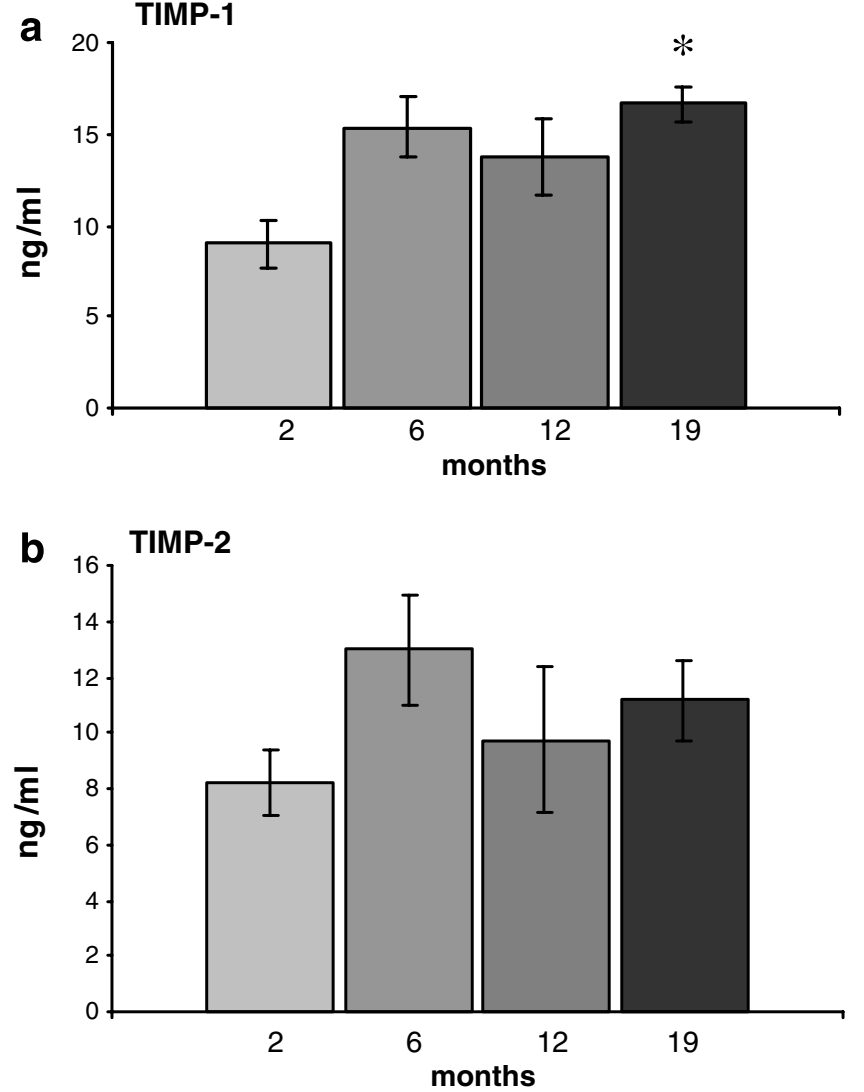

Fig. 5. Bar graph illustrating the age-dependent quantification of the specific metalloproteinase inhibitors ${ }^{*} p<0.05$ vs $2,6,12$ months.

B) leading to complete digestion of fibrillary collagen (Benyon and Arthur, 2001; Parks and Shapiro, 2001).

In our model we observed a significant decrease in MMP-1 activity during maturation and aging, suggesting that changes in the balance between synthesis and degradation could be responsible for the interstitial COL accumulation. The same pattern, to a lesser extent, was observed for MMP-2.

The opposite behaviour has been described during pulmonary development, where the extensive distribution of MMPs suggests a significant role of both MMP-1 and MMP-2 in the remodeling of the interstitium and of the epithelial basement membrane associated with fetal growth (Masumoto et al., 2005; Shannon and Deterning, 1997).

A pivotal extracellular control of MMP catalytic activity is accomplished by members of a specific family of inhibitors named tissue inhibitors of metalloproteinase (TIMP) (Selman et al., 2000). Among the currently identified four members of TIMP family (TIMP-1 to 4), TIMP 1 and 2 are the most relevant, since they inhibit the active form of MMPs (Baker et al., 1998; Gomez et al., 1997; Guedez et al., 1998).

The finding of increased levels of TIMP1 and 2 during aging suggests the hypothesis that a non-degrading fibrillary collagen microenvironment is prevailing (Selman et al., 2000). In conclusion these results suggest that, even in the aging lung, a progressive collagen accumulation occurs, involving several mechanisms that control the ECM turnover without a predominant role of any of them.

In particular, it seems that there is a lack of mechanisms normally involved in the active fibroplasias, i.e. a gene overexpression of TGF $\beta-1$, and COL-III, and a prevailing gradual dissociation due to an overbearing decrease of collagenolytic activity.

\section{Acknowledgement}

We thank Dr. Luigi Flaminio Ghilardini (Milan University, Italy) for graphic assistance.

\section{References}

Arthur, M.J.P., 1990. Matrix degradation in the liver. Semin. Liver dis. 10, $47-55$.

Abrass, C.K., Adcox, M.J., Raugi, G.J., 1995. Aging associated changes in renal extracellular matrix. Am. J. Phatol. 146, 742-752.

Angel, P., Baumann, I., Stein, B., Delius, H., Rahmsdorf, H.J., Herrlich, P., 1987. 12-O-tetradecanoyl-phorbol-13-acetate induction of the human collagen gene is mediated by an inducible enhancer element located in the $5^{\prime}$-flanking region. Mol. Cell. Biol. 7, 2256-2266.

Baker, A.H., Zaltsman, A.B., George, S.J., Newbay, A.C., 1998. Divergent effectsof tissue inhibitor of metalloproteinase-1, -2 , or -3 overexpression on rat vascular smooth muscle cell invasion, proliferation, and death in vitro. TIMP-3 promotes apoptosis. J. Clin. Invest. 110, 1478-1487.

Benyon, R.C., Arthur, M.J.P., 2001. Extracellular matrix degradation and the role of hepatic Stellate cells. Semin. Liver dis. 21, 373-384.

Brinckerhoff, C.E., Plucinska, I.M., Sheldon, C.A., O'Connor, G.T., 1986. Half-life of synovial cell collagenase mRNA is modulated by phorbol myristate acetate but not by all-trans-retinoie-acid or dexamethasone. Biochemistry 25, 6378-6384.

Chambered, R.C., Laurent, G.J., 1997. Colagens. In: Crystal, R.G., West, J.B., Weibel, E.R., Barnes, P.J. (Eds.), The Lung: Scientific Fondations. Lippincott-Raven Publishers, Philadelphia, pp. 707-727.

Chomczynski, P., Sacchi, N., 1987. Singl-step method of RNA isolation by acid guanidinium thyocyanate-phenol-chloroform extraction. Anal. Biochem. 162, 156-159.

D’Errico, A., Scarani, P., Colosimo, E., Spina, M., Grigioni, W.F., Mancini, A.M., 1989. Changes in alveolar connective tissue of the ageing lung. Virchows. Archiv. A. Pathol. Anat. 415, 137-144.

Ebihara, T., Venkatesan, N., Tanaka, R., Ludwig, M.S., 2000. Changes in extracellular matrix and tissue viscoelasticity in bleomycin-induced lung fibrosis. Am. J. Respir. Crit. Care. Med. 162, 1569-1576.

Enright, P.L., Kronmal, R.A., Manolio, T.A., schenker, M.B., Hyatt, R.E., 1994. Respiratory muscle strenght in the elderly: correlates and reference values. Am. J. Respir. Crit. Care Med. 149, 430-438.

Evers, B.M., Townsend, C.M., Thompson, J.C., 1994. Organ physiology of aging. Surg. Clin. North Am. 74, 2337.

Gagliano, N., Arosio, B., Grizzi, F., Masson, S., Tagliabue, J., Dioguardi, N., Vergani, C., Annoni, G., 2002. Reduced collagenolytic activity of matrix metalloproteinases and development of liver fibrosis, in the aging rat. Mech. Ageing Dev. 123, 413-425.

Green, F.H.Y., Pinkerton, K.E., 2004. Environmental determinantes of lung aging. In: Harding, R., Pinkerton, K.E., Plopper, C.G. (Eds.), The Lung: Development, Aging and the Environment. Elsevier, London, pp. 377-395.

Gomez, D., Alonso, D., Yoshiji, U., Thorgeirsson, P., 1997. Tissue inhibitors of metalloproteinases: structure, regulation and biological functions. Eur. J. Cell. Biol. 74, 111-122. 
Guedez, L., Stetler-Stevenson, W.G., Wolff, L., Wang, L., Fukushima, P., Mansoor, A., Stetler-Stevenson, M., 1998. In vitro super expression of programmed cell death of $\mathrm{B}$ cells by tissue inhibitor of metalloproteases-1. J. Clin. Invest. 102, 2002-2010.

Herron, G.S., Banda, M.J., Clark, E.J., Gavrilovic, J., Werb, Z., 1986. Secretion of metalloproteinases by stimulated capillary endothelial cell II. Expression of collagenases and stromelysin activities is regulated by endogenus inhibitors. J. Biol. Chem. 261, 2814-2818.

Ignotz, R.A., Massaguè, J., 1986. Transforming growth factor- $\beta 1$ stimulates the expression of fibronectin and collagen and their ibncorporation into the extracellular matrix. J. Biol. Chem. 261, 4337-4345.

Iyer, S.N., Gurujeyalakshmi, G., Giri, S.N., 1999. Effect of Pirfenidone on procollagen gene expression at the transcriptional level in Bleomycin hamster model of lung. JPET 289, 211-218.

Janssens, J.P., Herrmann, F., MacGee, W., Micjel, M.P., 2001. Cause of death in older patients with anatomo-pathological evidence of chronic bronchitis or emphysema: a case-control study based on autopsy findings. J. Am. Gerietr. Soc. 49, 571-576.

Laemmli, U.K., 1970. Clevage of structural proteins during the assembly of the head of bacteriophage T4. Nature 227, 680-685.

Limper, A.H., Roman, J., 1992. Fibronectin. A versatile Matrix protein with roles in thoracic development, repair and infection. Chest 101, $1663-1673$.

Lundback, B., Lindberg, A., Lindstrom, M., Ronmark, E., Jonsson, A.C., Jonsson, E., Larsson, L.G., Andersson, S., Sandstrom, T., Larsson, K., 2003. Obstructive ling disease in Northern Sweden Studies: not $15 \%$ but $50 \%$ of smokers develop COPD? Report from obstructive lung disease in northern Sweden studies. Respir. Med. 97, 115-122.

Malik, A., Saltoun, C.A., Yarnold, P.R., Grammer, L.C., 2004. Prevalence of obstructive airways disease in the disadvantaged elderly of Chicago. Allergy Asthma Proc. 25, 169-173.

Masumoto, K., de Rooij, J.D., Suita, S., Rottier, R., Tibboel, D., de Krijger, R.R., 2005. Expression of matrix metalloproteinases and tissue inhibitors of metalloproteinases during normal human pulmonary development. Histopatology 47, 410-419.
McCormick, L.L., Zhang, Y., Tootell, E., Gilliam, A.C., 1999. Anti-TGF$\beta$ treatment prevents skin and lung fibrosis in murine sclerodernatous graft-versus host disease: a model for human sceroderma. J. Immunol. 163, 5693-5699.

Meyer, K.C., 2005. Aging. Proc. Am. Thorac. Soc. 2, 433-439.

Mozes, M.M., Bottinger, E.P., Jacott, T.A., Kopp, J.B., 1999. Renal expression of fibrotic matrixproteins and the transforming growth factor- $\beta$ (TGF- $\beta$ ) isoforms in TGF- $\beta$ transgenic mice. J. Am. Soc. Nephrol. 10, 271-280.

Nicoletti, A., Sassy-Prigent, C., 1996. An alternative quantitative polymrase chain reaction method. Anal. Biochem. 236, 229-241.

Selman, M., Ruiz, V., Cabrera, S., Segura, L., Ramirez, R., Barrios, R., Pardo, A., 2000. TIMP-1, $-2,-3$, and -4 in idiopathic pulmonary fibrosis. A prevailing non degenerative lung microenvironment? Am. J. Physiol. Lung Cell. Mol. Physiol. 279, L562-L574.

Parks, W.C., Shapiro, D.S., 2001. Matrix metalloproteinses in lung biology. Respir. Res. 2, 10-19.

Peterson, D.D., Pack, A.I., Silage, D.A., Fishman, A.P., 1981. Effects of aging on ventilatory and occlusion pressure responses to hypoxia and hipercapnia. Am. Rev. Respir. 124, 387-391.

Shannon, J.M., Deterning, R.R., 1997. Epithelial-mesenchymal interactions, in lung development. In: Mc.Donald, J.A. (Ed.), Lung Growth and Development. Marcel Dekker, inc., New York, pp. 81-118.

Sporn, M.B., Roberts, A.B., Wakefield, L.M., de Combrigghe, B., 1987. Same recent advances in the chemistry and biology of transforming growth factor-beta. J. Cell. Biol. 105, 1039-1045.

Steward, W., 1999. Marimastat (BB2516) current status of development. Cancer Chem. Pharmacol. 43 (Suppl.), S56-S60.

Tack, M., Altose, M., Cherniack, N., 1982. Effect of aging on the perception of resistive ventilatory loads. Am. Rev. Respir. Dis. 126, 463-467.

Tierney, G.M., Griffin, N.R., Stuart, R.C., Kasem, H., Lynch, J.T., Brown, P.D., Millar, A.W., Steele, R.J., Parsons, S.L., 1999. A pilot study of the safety and effects of the matrix metalloproteinases inhibitor marimastat in gastric cancer. Eur. J. Cancer 35, 563-568. 